\title{
A new cucullanid species (Nematoda) from the freshwater fish Thorichthys helleri (Cichlidae) in Mexico
}

\author{
J. M. CASPETA-MANDUJANO ${ }^{1}$, G. SALGADO-MALDONADO² ${ }^{2}$ E. MARTÍNEZ-RAMÍREZ ${ }^{3}$
}

\begin{abstract}
${ }^{1}$ Laboratorio de Parasitología de Animales Silvestres, Facultad de Ciencias Biológicas y Centro de Investigaciones Biológicas, Universidad Autónoma del Estado de Morelos, Av. Universidad No. 1001, Col. Chamilpa, C.P. 62209, Cuernavaca, Morelos, México, E-mail: caspeta@uaem.mx; ${ }^{2}$ Laboratorio de Helmintología, Instituto de Biología, Universidad Nacional Autónoma de México, A.P. 70-153, 04510, México, D.F., México; ${ }^{3}$ Centro Interdisciplinario de Investigación para el Desarrollo Integral Regional Unidad Oaxaca, Instituto Politécnico Nacional. Hornos No. 1003, Col. Noche Buena, Santa Cruz Xoxocotlán, Oaxaca, México.
\end{abstract}

\begin{abstract}
Summary
A new nematode species, Cucullanus oaxaquensis n. sp., is described from specimens recovered from the intestine of Thorichthys helleri Steindachner, 1864 from the Río Modelo, Los Chimalapas, state of Oaxaca, Mexico. It is characterized largely by possesing unusual features among Cucullanus spp., i.e., net-like sculpture on the surface of eggs, a pair of small papillae near tail tip of females and a small terminal sclerotized structure at tail tip of both males and females. This findig represents the fouth species reported from freshwater fishes in Mexico and the second for cichlid fishes.
\end{abstract}

Keywords: Nematoda; Cucullanus; Cichlidae; Thorichthys helleri; Oaxaca; Mexico

\section{Introduction}

The yellow cichlid Thorichthys helleri (Steindachner, 1864) (Cichlidae) ranges from Guatemala to Mexico, inhabiting rivers (Miller, 2005). Available data about its parasites in Mexico suggest a high richness, which included 30 species of Trematoda, three of Monogenea, one of Cestoda, two of Acanthocephala and seven of Nematoda (Salgado-Maldonado, 2006). Examination of this host species captured from the Río Modelo in the state of Oaxaca, Mexico, revealed the presence of a new species of nematode belonging to the genus Cucullanus Müller, 1777 which is described herein.

\section{Material and methods}

Fishes were collected by using an electro-fishing machine from the Río Modelo, Los Chimalapas $\left(17^{\circ} 08^{\prime} 5.2^{\prime \prime} \mathrm{N}\right.$, $94^{\circ} 44^{\prime} 42^{\prime \prime}$ W), state of Oaxaca, Mexico. The nematodes recovered from the intestine were fixed in hot $4 \%$ formaldehyde and cleared with glycerine for examination. Drawings were made with the aid of a Nikon microscope drawing attachment. After examination, the specimens were stored in vials with $70 \%$ ethanol. Three specimens were dried by critical point method for study with a scanning electron microscope (SEM). All measurements are given in $\mu \mathrm{m}$ unless otherwise stated. Type specimens have been deposited in the National Helminthological collection of the Institute of Biology, National Autonomous University of Mexico (UNAM), Mexico City, and in the Parasitological Collection of the Autonomous University of Morelos State, Mexico.

\section{Results}

Cucullanus oaxaquensis n. sp.

(Figs. 1 - 17)

General: Medium sized nematodes. Head end rounded. Oral opening dorsoventrally elongate, surrounded by a collarete armed with numerous minute denticles on each side. Four submedian cephalic papillae and pair of lateral amphids present (Fig. 11) Pseudobuccal cavity well developed (oesophastome) as wide as posterior part of oesophagus. Oesophagus long and narrow, expanded at both extremities, it open into intestine through a valve. Nerve ring encircling oesophagus at its middle length (Figs. 1, 2). Deirids simple, slightly asymmetrical, just anterior to oesophago-intestinal juntion (Figs. 1, 2, 15). Excretory pore situated short distance below end of oesophagus (Figs. 1, 2). Tail of both sexes conical, ending in small terminal sclerotized structure at tip, being more conspicuos in females (Figs. 6, 7, 8, 12, 14, 17).

Male (5 specimens, holotype in parentheses): Length 5.25 - 6.80 (6.70) mm width 275 - 337 (337). Entire oesophagus $681-750$ (750) (11 - 13\% of body length), its minimum width $73-98$ (98), maximum width in anterior region $142-150$ (150). Nerve ring, excretory pore and deirids 293 - 362 (362), $662-862$ (862) and 337 718 (718), respectively, from anterior extremity. Length of 

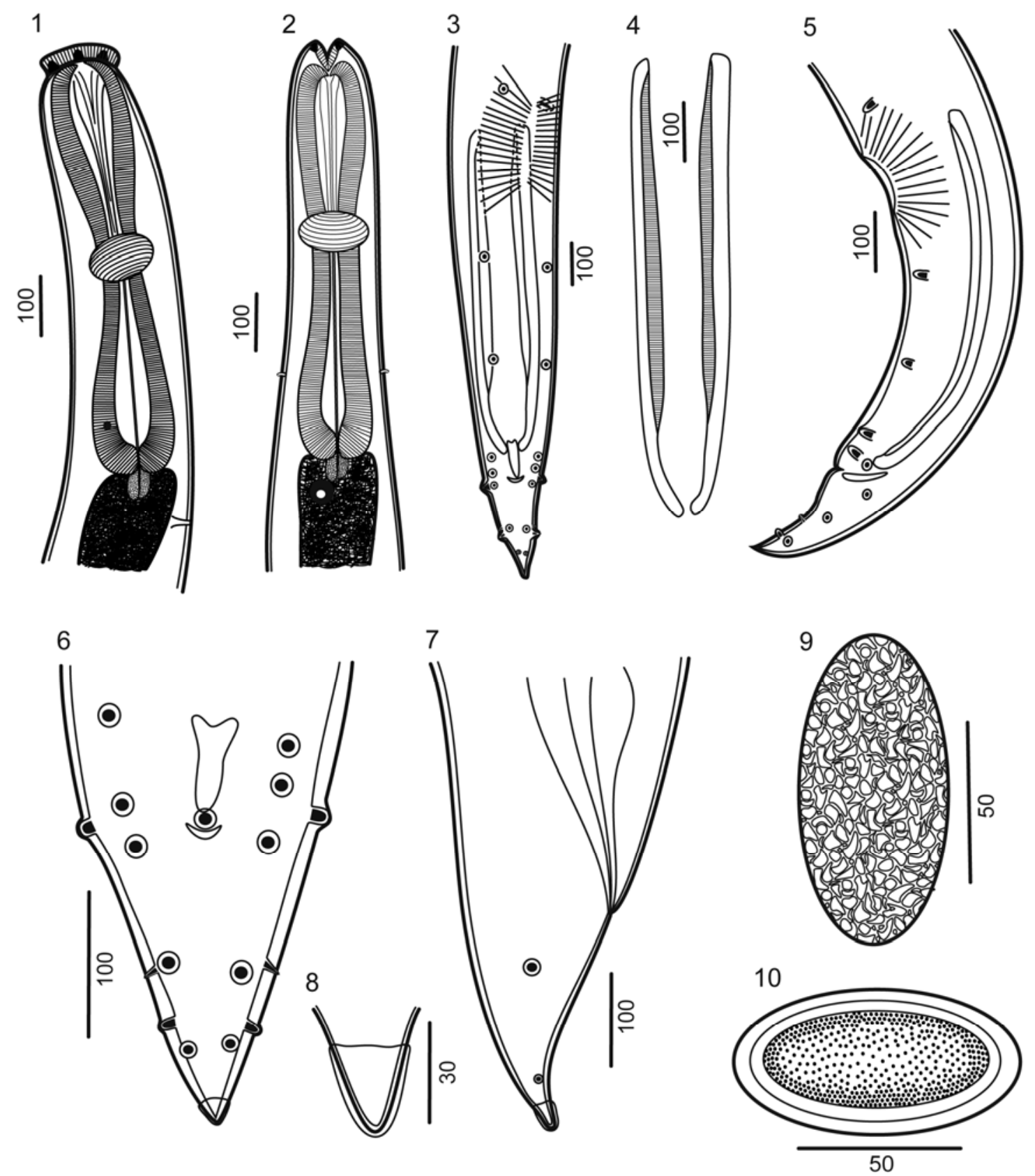

Figures 1-10. Cucullanus oaxaquensis n. sp. (1) Anterior end of male, lateral view. (2) Anterior end of female, ventral view. (3, 5) Posterior end of male, ventral and lateral views. (4) Spicules. (6) Posterior end of male, ventral view. (7) Posterior end of female, lateral view. (8) Detail of tail tip. $(9,10)$ Eggs.

spicules 575 - 825 (725), provided with membranous alae, which does not run a long of whole lenght (Fig. 4). Gubernaculum well sclerotized, 76 - 87 (76) long (Figs. 3, $5,6)$. Ventral preanal sucker present, surrounded by first and second pair of precloacal papillae (Figs. 3, 5). Caudal papillae consisting of an unpaired median papilla present on anterior cloacal lip and 11 pairs of papillae, including phasmids: 3 pairs preanal (pair 1 anterior and pair 2 posterior to ventral sucker, respectively; pair 3 between sucker and cloaca but closer to latter), 4 pairs adcloacal (3 subventral [4-6], 1 lateral [7] situated at level of, or more frequently, slightly posterior to pair 6) and 4 pairs of postcloacal (pairs 8 ans 10 subventral; pair 8 subdorsal, follow papillae numbering proposed by Petter (1974), small phasmids situated slightly anterior to or at level of pair 8. Tail conical $175-275$ (212) long, ending in small terminal sclerotized structure at tip $12-35$ (35) long (Figs. $3,5,6,16)$.

Female (5 specimens, allotype in parentheses): Length 9.88-12.15 (11.83) mm, width 497 - 537 (512). Entire oesophagus $850-987$ (987) (8-10\% of body length), its minimum width 125 - 137 (137), maximum width in posterior region $212-230$ (212). Nerve ring, excretory pore and deirids $312-412$ (312), $0.987-1.12(0.987) \mathrm{mm}$ and $762-900$ (762), respectively, from anterior extremity. Vulva postequatorial, $6.00-7.16(6.93) \mathrm{mm}$ from cephalic end. Vulvar lips elevated. Uteri opposed, containing immature and mature eggs, 92 - 95 x 50 - 52, surface 

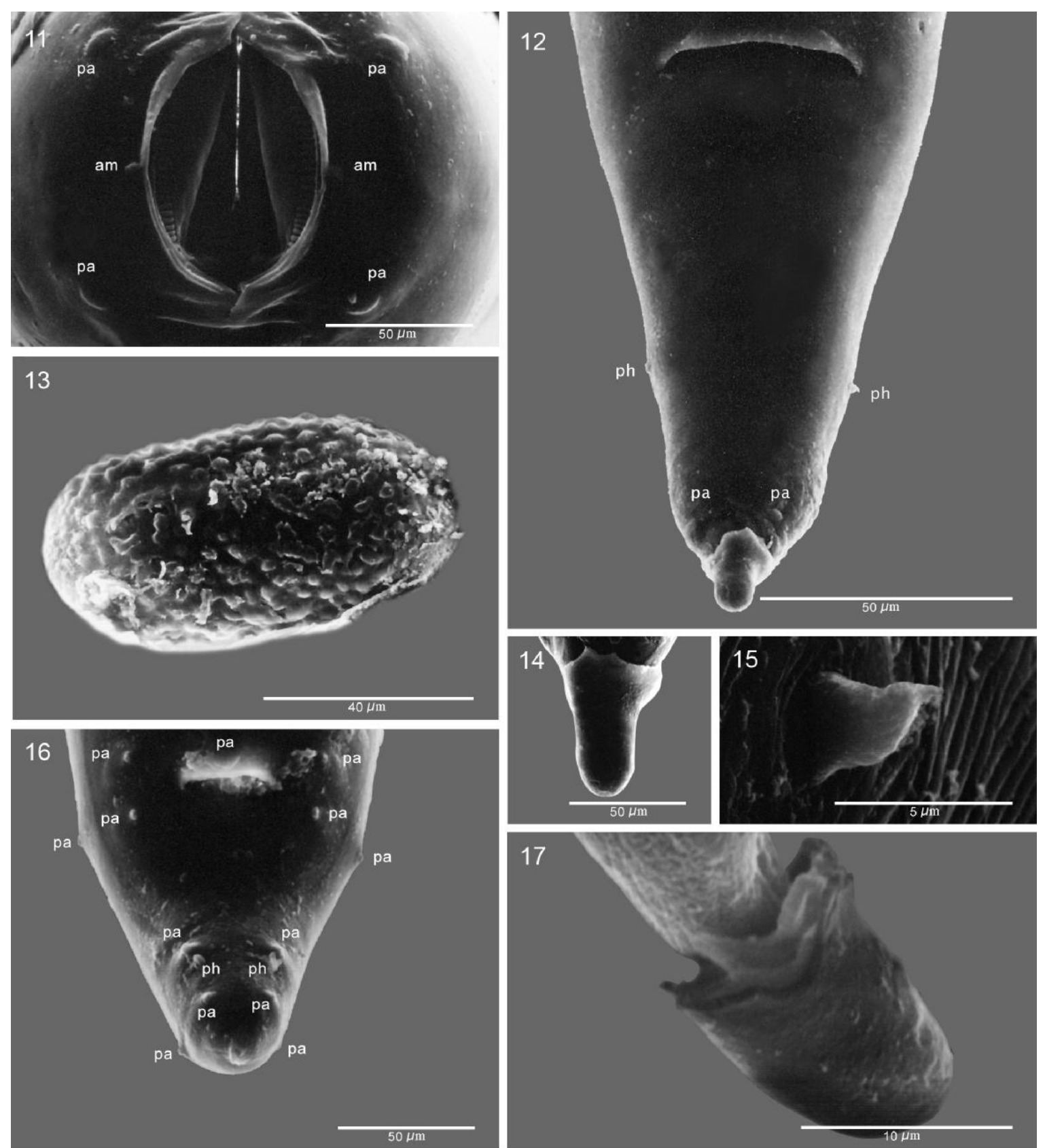

Figures 11-17. Cucullanus oaxaquensis n. sp., scanning electron micrographs. (11) Cephalic end of female, apical view. (12) Tail of female, ventral view. (13) Egg. (14) Tail tip of female. (15) Deirid. (16) Tail of male, ventral view. (17) Tail tip of female, lateral view. Abbreviations: am - amphid, pa - papilla, ph - phasmid.

sculturate (Figs. 9, 10, 13). Tail conical, 206-262 (233) long, ending in small terminal sclerotized structure at tip, $17-28$ (28) long (Figs. 7, 8, 12, 14). A pair of small lateral papillae (phasmids) present near mid-length of tail and a pair of small subventral papillae present near tip (Figs. 7, 12).

\section{Taxonomic summary}

Type host: Thorichthys helleri Steindachner, 1864 (Cichlidae).

Site of infection: Intestine.

Type locality: Río Modelo, Ciudad Cuautemoc, Los
Chimalapas, State of Oaxaca, Mexico.

Prevalence and range of intensity: $40 \%$ (10 fishes examined/4 fishes infected) 2-4 nematodes.

Date of collection: March 2009.

Etymology: The specific epithet relates to the Mexican State of Oaxaca, where this species was found.

Deposition of types: Holotype, allotype and paratypes in the Institute of Biology, UNAM, in Mexico, City (CNHE6940, 6941, 6942) and Faculty of Biology, Parasitological Collection of the Universidad Autónoma del Estado de Morelos, Mexico (COPAUAEM N-374). 


\section{Discussion}

Genus Cucullanus contains a large number of species parasitizing various freshwater, brackish-water and marine fishes around the world, more rarely they are found in aquatic turtles (Petter, 1974). Their morphology is rather uniform, therefore, some authors prefer to deal with these parasites according to their zoogeographical regions (e.g., Petter, 1995; Caspeta-Mandujano et al., 2000; Moravec et al., 2005; Cabañas-Carranza \& Caspeta-Mandujano, 2007). At present, 19 species and subspecies of Cucullanus have been reported from freshwater fishes in the Americas, 6 from North America (C. truttae Fabricius, 1794; $C$. sphaerocephalus (Rudolphi, 1809); C. clitellarius Ward et Magath, 1917; C. caballeroi Petter, 1977; C. mexicanus Caspeta-Mandujano, Moravec et Aguilar-Aguilar 2000; $C$. angeli Cabañas-Carranza et Caspeta-Mandujano, 2007) and 13 from South America (C. pinnai Travassos, Artigas et Pereira, 1928; C. zungaro Vaz et Pereira, 1934; C. pauliceae Vaz et Pereira, 1934; C. mogi Travassos, 1948; C. colossomi Díaz-Ungría, 1968; C. oswaldocruzi Santos, Vicente et Jardim, 1979; C. grandistomis (Ferraz et Thatcher, 1988); C. brevispiculus Moravec, Khon et Fernandes, 1993; C. pimelodellae Moravec, Khon et Fernandes, 1993; C. pseudoplatystomae Moravec, Khon et Fernandes, 1993; C. rhamphichthydis Moravec, Khon et Fernandes, 1997; C. pinnai pterodorasi Moravec, Khon et Fernandes, 1997; C. heliomartinsi Moreira, Rocha et Costa 2000 (Caspeta-Mandujano et al., 1999, 2000; Moravec, 1998; Moreira et al., 2000; Cabañas-Carranza \& CaspetaMandujano, 2007). Of them, only three species have been recorded in Mexican freshwater fishes, C. angeli, $C$. caballeroi and C. mexicanus (Caspeta-Mandujano, 2005).

By the presence of a ventral sucker and gubernaculum, $C$. oaxaquensis n. sp. is easily distinguished from C. grandistomis, C. pimelodellae and C. mogi, the ventral sucker is lacking in the first two species and the gubernaculum in the later. In addition, $C$. mogi has narrow caudal alae, which has not been reported in any other freshwater species of Cucullanus. Even though males of C. rhamphichthydis are unknown, a comparison of the females was sufficient to distinguish it from the new species. In C. rhamphichthydis the deirids and the excretory pore are located far from the posterior end of oesophagus. All the remaining species have a ventral sucker which is shortly oval, surrounded by the first two pairs of precloacal papillae, except in $C$. mexicanus, in which the ventral sucker is conspicuously elongated and only the first pair of preanal papillae is situated near the posterior end of the precloacal sucker.

By the position of deirids, excretory pore, presence of unpaired papilla in the anterior cloacal lip and the location of phasmids (slightly up or at level of last 8 pair of postcloacal papillae), the new species differs from all congeners, except with Cucullanus angeli. However they can be easily distinguished by the length of spicules and gubernaculum $(175-475$ vs. $575-825$ and $76-87$ vs. $107-$ 175 , respectively), absence of membranous alae in spicules, which is present in the new species, ornamentation on surface' eggs, which is absent in $C$. angeli and presence of small terminal sclerotized structure at tail tip in both sexes. The presence of an unpaired papilla located in the anterior cloacal lip, seems to be unique among all species of Cucullanus reported from freshwater fishes; because these features have been only reported from one freshwater species of Cucullanus, $C$. angeli (Cabañas-Carranza \& Caspeta-Mandujano, 2007), it seems to be more common in Cucullanus spp. from marine waters (i.e. Cucullanus pedroi, C. bonaerensis) (Lanfranchi et al., 2004; Timi \& Lanfranchi, 2006). The location of phasmids in freshwater Cucullanus spp. has been reported slightly anterior or at level of last two pairs of postcloacal papillae (i.e. C. pseudoplatystomae, C. sphaerocephalus) or posterior or at level of last pair of papillae (i.e. $C$. $c a$ balleoi, C. mexicanus, C. pauliceae (Moravec, 1998; Caspeta-Mandujano, 2005).

Moravec et al. (2005) reported a new species of Cucullanus, C. oceaniensis from the intestine of Anguilla spp. from Polynesia and Melanesia, which is rather similar to $C$. oaxaquensis n. sp. However, C. oaxaquensis differs from C. oceaniensis by the length of spicules and gubernaculum (575 - 825 and $76-87$ vs. $668-1,022$ and $111-135)$, size of eggs (92 - 95 long and $50-52$ wide vs. $75-84$ long and $42-45$ wide), surface of eggs, which is smooth in $C$. oceaniensis, and presence of small terminal sclerotized structure at tail tip in both sexes, which is absent in C. oceaniensis.

The new species can be differentiated from all congeners so far reported all over the world by possessing three unusual features: 1) a net-like sculpture on the surface of eggs, 2) a pair of small papillae near the females tail tip, and 3) a small terminal sclerotized structure at tail tip. The findings of the new species in $T$. helleri represents the second species reported from Cichlidae.

\section{Acknowledgments}

The authors' thanks are due to Berenit Mendoza Garfias from the UNAM and Alejandro de Jesús Medrano Silva from the UAEM for the technical assistance with SEM and micrographs. Part of this study was supported by the operating grant UNAM, DGAPA, PAPIIT: IN 229807 to Guillermo Salgado Maldonado.

\section{References}

Cabañas-Carranza, G., Caspeta-Mandujano, J. M. (2007): A new cucullanid species from the freshwater fish Vieja intermedia (Günther, 1962) (Cichlidae) in Mexico. J. Parasitol., 93: 646 - 649. DOI: 10.1645/GE-987R.1

Caspeta-Mandujano, J. M. (2005): Nematode Parasites of Freshwater Fish of Mexico: Key to Species, Description and Distribution. Universidad Autónoma del Estado de Morelos, Cuernavaca, Morelos, México, 175 pp.

Caspeta-Mandujano, J. M., Moravec, F., AguilarAguilar R. (2000): Cucullanus mexicanus n. sp. (Nema- 
toda: Cucullanidae) from the intestine of the freshwater catfish Rhamdia guatemalensis (Pimelodidae) in Mexico. Helminthologia, 37: 215 - 217

Caspeta-Mandujano, J. M., Moravec, F., SalgadoMALDONADO, G. (1999): Observation on cucullanid nematodes from freswater fishes in Mexico, including Dichelyne mexicanus sp. n. Folia Parasitol., 46: 289 - 295 LANFranchi, A. L., Timi, J. T., SARDElla, N. H. (2004): Cucullanus bonaerensis n. sp. (Nematoda: Cucullanidae) parasitizing Urophycis brasiliensis (Pisces: Phycidae) from Argentinean waters. J. Parasitol., 90: 808 - 812. DOI: 10.1645/GE-3276

Miller, R. R., Minckley, W. L., Norris, S. M. (2005): Freshwater Fishes of Mexico. The University of Chicago Press, Chicago Illinois, $490 \mathrm{pp}$.

MorAVEC, F. (1998): Nematodes of Freshwater Fishes of the Neotropical Region. Academia, Praha, 464 pp.

Moravec, F., Sasal, P., Würtz, J., TARAschewski, H. (2005): Cucullanus oceaniensis sp. n. (Nematoda: Cucullanidae) from Pacific eels (Anguilla spp.). Folia Parasitol., 52: $343-348$
Moreira, N. I. B., Rocha, G. N., Costa, H. M. A. (2000): A new nematode species (Seuratoidea, Cucullanidae) parasitizing Parauchenipterus striatulus (Steindachner, 1876) (Pisces, Auchenipteridae) in Brazil. Mem. Inst. Oswaldo Cruz, 95: 39 - 41. DOI: 10.1590/S007402762000000100005

PeTter A. 1974: Essai de classification de la famille des Cucullanidae. Bulletin du Museum National D'Historie Naturelle, 3e série, No. 255, Zoologie, Biologie et Ecologie Anaimales, 177: 1469 - 1490

PetTer, A. J. (1995): Nematodes de poissons du Paraguay. VIII. Habronematoidea, Dracunculoidea et Ascaridoidea. Rev. Suisse Zool., 102: 89 - 102

SAlgado-MALDONADO, G. (2006): Checklist of helminth parasites of freshwater fishes in Mexico. Zootaxa, 1324: 1 $-327$

Timi, J. T., LANFrANCHI, A. L. (2006): A new species of Cucullanus (Nematoda: Cucullanidae) parasitizing Conger orbignianus (Pisces: Congridae) from Argentinean waters. J. Parasitol., 92: 151 - 154. DOI: 10.1645/GE-3530.1 